\title{
Numerical investigation of granular filter under the bed of a canal
}

\author{
Fatemeh Jafari ${ }^{1} \cdot$ Farzin Salmasi $^{1}$ (D) John Abraham $^{2}$
}

Received: 27 April 2019 / Accepted: 1 July 2019 / Published online: 8 July 2019

(c) The Author(s) 2019

\begin{abstract}
To protect canal beds against erosion and to prevent seepage from the bottom or side of a canal, impermeable linings are often used. These linings can suffer from several problems including damage due to uplift pressure when the groundwater table is high. Thus, it is necessary to provide a drainage system under the hard lining of the canal to reduce the water pressure, especially at the end of the operation season, when the canal is empty. This work evaluates the performance of a drainpipe with a filter envelope located under the bed of canal. The solution method uses the finite element method to analyze and minimize uplift force. Various combinations of drain diameters, envelop thicknesses, depths of drain under the canal invert, and groundwater surfaces are considered. Simulation results indicate that with increasing drain diameter and depth of drain under the bed of canal, the groundwater surface declines and the uplift force is reduced. The use of a filter envelope around the drainpipe for decreasing hydrostatic pressure is found to be effective. Linear and nonlinear regression equations for predicting the pressure head in canal bed centerline are provided.
\end{abstract}

Keywords Canal · Drainage system · Granular filter · Groundwater head · Uplift

\section{List of symbols}

D Diameter of drain

$H \quad$ Water level above the bedrock

$K_{\mathrm{f}} \quad$ Hydraulic conductivity of filter

$K_{\mathrm{s}} \quad$ Hydraulic conductivity of soil

$l \quad$ Length of the drainage

$P \quad$ Pressure head

$R^{2} \quad$ Determination coefficient

RMSE Root mean square error

$t \quad$ Thickness of filter

$V \quad$ Velocity of flow

$Y \quad$ Drain elevation from bedrock to middle of drain

$\Delta h \quad$ Total head loss

$\gamma_{\mathrm{w}} \quad$ Unit weight of water

Farzin Salmasi

Salmasi@tabrizu.ac.ir

Fatemeh Jafari

mail.jafari65@yahoo.com

John Abraham

jpabraham@stthomas.edu

1 Department of Water Engineering, Faculty of Agriculture, University of Tabriz, P.O. Box: 5166616471, Tabriz, Iran

2 School of Engineering, University of St. Thomas, Minnesota, 2115 Summit Avenue, St. Paul, MN 55105, USA

\section{Introduction}

Mathematical models have found a broad range of uses in several fields of the natural sciences. Regarding agricultural drainage, various mathematical models have been used in research and applied engineering to optimize the design of drainage networks (Chau 2006; Gurovich and Oyarce 2015). This body of research allows the application of mathematical models to the design and evaluation of drainage networks.

There are many techniques and structures that can be used to handle excess water and salts that may be present in agricultural lands. Drainage can be used to provide an adequately oxygenated environment that is suitable for plant growth. The general goal of these methods is to maintain adequate levels of water and air in proportions that improve plant growth and sustain soil quality (Ayars et al. 2006; Ritzema et al. 2006, 2008; Naz et al. 2009).

An increase in groundwater levels is important for design considerations for multiple reasons. An increase in groundwater level may lead to an increase in the pressure that is exerted on the bottom and sides of the canal. The internal stress that is caused by this pressure (and by swelling soils) may weaken the canal concrete lining and cause cracks and failures in the materials (Fahmi et al. 2015). An exhibit of a concrete lining failure is provided in Fig. 1.

(2115 Summit Avenue, St. Paul, MN 55105, USA 


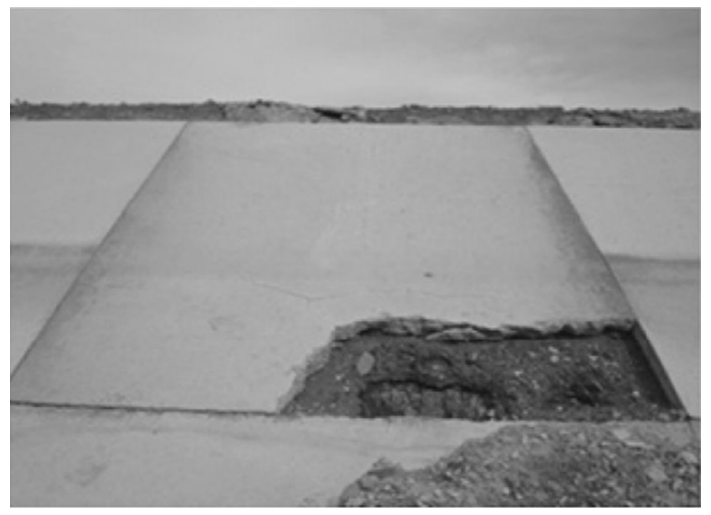

Fig. 1 Failures in the concrete lining (Fahmi et al. 2015)

Singh (2009) obtained an analytical method that can be used to calculate the groundwater head in horizontal aquifers. The solutions are appropriate for the practical situation of shallow-depth drains in an aquifer. Oyarce et al. (2017) simulated the hydraulic behavior of an ideal drain. They characterized the behavior by an entrance resistance factor; simulation results indicate that the water entrance resistance factor must be considered in the design of a drainage network. The hydraulic behavior of the agricultural drain depends on its geometric characteristics. Oyarce et al. (2016) completed an experimental investigation of agricultural drains. That work showed that the effects of perforation density and envelope screens were determined by water extraction efficiency for small hydraulic head conditions.

Palacios Velez et al. (2004) studied the large variability of soil hydraulic conductivity $(k)$, particularly in alluvial soils. They showed that for small-plot drainage (5-10 ha), at least one conductivity measurement is recommended for each hectare and five measurements for each plot.

Bucur and Savu (2006) showed that the removal of soil moisture is possible with the construction of intercepting drainage structures. Spring water that concentrates on land can be collected using shafts that are outfitted with drains and bottom filters.

WinBo et al. (2015) found that large-sized testers are required for high-capacity drainage. It has been shown that drain capacity decreases with increasing hydraulic gradient. It has also been shown that the decrease in discharge capacity is quite significant for low vertical pressures. Salmasi et al. (2017) investigated the reduction in the already-mentioned pressure forces that are exerted on longitudinal drains with underlined canals. That research showed that utilization of drainpipes underneath the canal been can be effective for reducing the groundwater depth and consequently the uplift force.

Chandio et al. (2013) simulated both horizontal and vertical drainage systems that are used to handle waterlog problems on the Rohri Canal in Khairpur District, Pakistan. They showed that vertical or horizontal drains alone are not capable of reducing waterlogging. In order to be effective, a drainage system should be installed close to the canal so that the combined drainage systems can work together. The authors also showed that a combined drainage system (tube wells and a horizontal drain) is more effective at maintaining water table levels.

Samani et al. (2006) developed analytical solutions to a drainage problem and provided computational algorithms that can be used to calculate drawdown and discharge to horizontal drains. The software works in a Laplace domain and then translates the results to real time. The authors found that the total discharge to the drain was inversely proportional to the drain elevation. They also showed that by decreasing the elevation, it was possible to increase the difference between the head at the drain and the surrounding aquifer. Furthermore, the discharge decreases over time because of the reduction in water head.

Singh et al. (2007) showed fluctuating water levels during an exponential recharge and evapotranspiration that varies with depth. The result of this analysis was that it is possible to predict water table fluctuations in both arid and semiarid regions and for both sloping and non-sloping lands.

Nourani et al. (2017) studied optimum location of drains in gravity dams. They implemented finite element method to investigate the effect of drain rows on uplift force under the dam foundation. They found optimum values for diameter of drain, distance of drains (in plan), and distance of drains from heel of dam. In this optimum point, the uplift force under the dam has minimum value that creates the design to be economically.

The present study extends the prior work by focusing on water pressure under the canal invert in the presence of a granular filter. For this purpose, several numerical models are simulated using the finite element (FE) method by applying SEEP/W (2012). In order to evaluate the drainage capability of the subgrade soil in its natural condition and to find out whether the base soil needs a drainage system, or whether it can drain the seepage flow under the canal lining without inducing excess pore pressure, some preliminary tests were simulated. In the tests, no drainage systems were used. These models were carried out with water levels at 50, 80 , and $120 \mathrm{~cm}$ above the bottom of the canal. The ultimate goal of the present research is to utilize the numerical methods to quantify the uplift that is exerted on the canal lining and to optimize water discharge. In particular, geometric parameters such as the drain diameter, the filter thickness, and drain depth below the canal will be modified and the impact on both the water table and uplift will be found. With this approach, rational design recommendations can be given for the use of filters in these water flow situations. 


\section{Materials and methods}

\section{Basic concepts}

Two common ways of managing underground water are through open ditchers (see Fig. 2a) and underground perforated piping (see Fig. 2b). Open ditches are simple structures that collect water and can be used to remove surface runoff. This runoff can cause farming losses or can interfere with machinery or other agricultural processes. Examples of past researches that deal with this topic include Scholz and Trepel (2004), Kroger et al. (2008), and Jia et al. (2011).

Underground piping systems typically consist of a hydraulic network of smooth and/or corrugated perforated plastic tubes buried at a specified distance from each other. They primarily are used to lower the water table level in unconfined aquifers (Stuyt et al. 2005; Ritzema et al. 2008; Gurovich and Oyarce 2015).

As discussed by Nijland et al. (2005), drainage pipe perforations or slots in the field drainage pipes must balance the following two characteristics:

- To have the largest possible size to limit water entrance resistance and

- To be as small as possible to prevent soil particles from clogging the tube.

For a partially drained state near a gravel drain, pore water flows toward the drain and is driven by the total head variation. It is usually assumed that the drain has an infinite permeability and consequently the pore water pressure is zero there.

The total head loss between two points, which is expressed here as $\Delta h$, can be written in terms of excess pore water pressure, $u$, at the center of the drains, i.e.,

$\Delta h=\frac{u}{\gamma_{\mathrm{w}}}$

where $\gamma_{\mathrm{w}}$ is the weight density of water. The flow of pore water through the porous material is expressed using Darcy's law as

$v=k \frac{\Delta h}{l}=\left(\frac{k}{l}\right) \Delta h$
The symbol $V$ represents fluid velocity, while the symbol $k$ is the hydraulic conductivity of the soil. Finally, the symbol $l$ represents the length of the drainage path (Yamamoto et al. 2009).

The continuity equation is derived from the Dupuit's assumptions results in the Boussinesq's equation, which is a nonlinear partial differential equation of second order. The groundwater flow equation over a sloping impervious layer is given as

$\left(\frac{\partial h}{\partial x}\right)^{2}+h\left(\frac{\partial^{2} h}{\partial x^{2}}\right)-\alpha\left(\frac{\partial h}{\partial x}\right)+\frac{R(t)-E(h)}{k}=\frac{f}{k} \frac{\partial h}{\partial t}$

where $h$ is the height of water table above the drain at a distance $x$ and time $t$. The symbol $\alpha$ represents the slope of the impermeable barrier having a small value such that $\alpha=\sin \alpha \sim \tan \alpha$; the symbol $k$ is the hydraulic conductivity; $f$ represents the drainable porosity of the aquifer; $R(t)$ is the recharge rate; and $E(h)$ indicates the depth-dependent rate of evaporation-transpiration (ET) (Singh et al. 2007).

\section{Performance evaluation of models}

In order to assess the quality, performance measures are used to compare modeled values with their corresponding observed values. The following metrics are used:

I. Root mean square error (RMSE)

$$
\operatorname{RMSE}=\sqrt{\frac{\sum_{i=1}^{N}\left(y_{\mathrm{p}}-y_{0}\right)^{2}}{N}}
$$

II. Coefficient of determination $\left(R^{2}\right)$

$$
R^{2}=1-\frac{\sum_{i=1}^{N}\left(y_{0}-y_{\mathrm{p}}\right)^{2}}{\sum_{i=1}^{N}\left(y_{0}-\bar{y}_{0}\right)^{2}}
$$

The symbol $N$ represents the number of observations. The terms $y_{0}, y_{\mathrm{p}}, \bar{y}_{0}$, and $\bar{y}_{\mathrm{p}}$ indicate the observed data, the predicted data, the mean of observed data, and the mean
Fig. 2 Subsurface drainage by a open ditches and $\mathbf{b}$ underground pipes
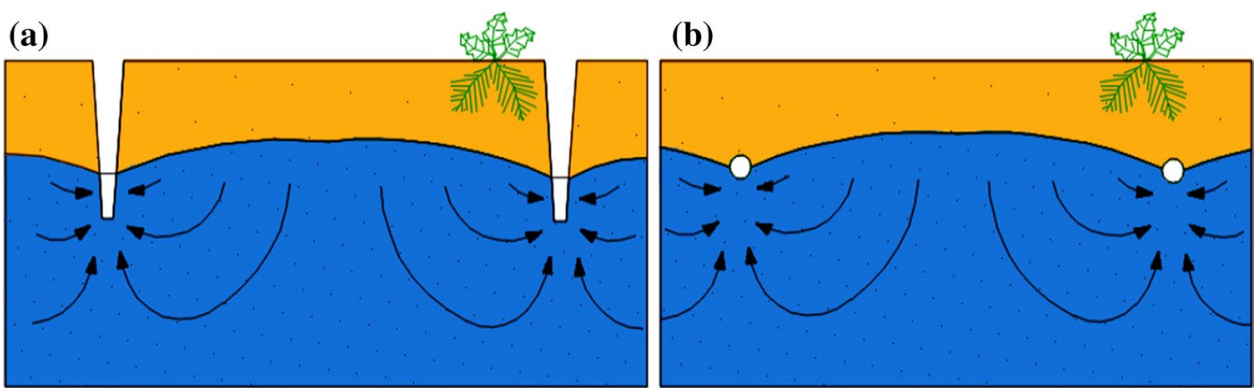
of predicted data, respectively. The RMSE metric ranges from 0 for a perfect model to higher values of real numbers. Values of the RMSE are a measure of the goodness of fit between the observations and modeled values. The error measure mean square error (MSE) is also used, and it behaves similar to RMSE.

The coefficient of determination defines the percentage of the total variance in the observed data that can be described by the model. High $R^{2}$ values show better agreement between predicted and observed values.

\section{Numerical simulation}

As intimated earlier, flow of water through soils is a fundamental process in geotechnical and geo-environmental engineering. It helps determine the seepage loss from a water reservoir and can be used as a water source for commercial or residential uses. The pore pressure of the flow is also of particular concern in engineering; in particular, it can adversely affect hydraulic structures.

As mentioned earlier, the FE method is used to complete the numerical solution. The software program used for this analysis is SEEP/W. This software is used for generating data for a wide variety of different scenarios. The solution is continuous so that results are provided at all locations within the solution domain.

The geometry of a model is defined in Fig. 3. The model canal has a trapezoidal shape, with a bottom width of $2 \mathrm{~m}$, side slopes of 1:1.5 (vertical: horizontal), a canal height of $1.5 \mathrm{~m}$, and height of side wall of $21.2 \mathrm{~m}$. The bedrock depth, from the bottom of canal, is $20 \mathrm{~m}$, and the service road of the canal is $3 \mathrm{~m}$. With these dimensions, the total width is $130 \mathrm{~m}$.

The canal cross section is trapezoidal, and the hydraulic conductivity for the porous media was taken as a typical value of $10^{-5} \mathrm{~m} / \mathrm{s}$. The drainage filter is designed with a hydraulic conductivity of $10^{-3} \mathrm{~m} / \mathrm{s}$ which is 100 times that of the soil hydraulic conductivity. This allows low resistance for flow through the drain pipes. Figure 3 shows a schematic view of the positions of drain pipe including with some dimensions annotated.

Necessary input information for the simulation are the hydraulic conductivities of the soil $\left(k_{\mathrm{s}}\right)$ and filter $\left(k_{\mathrm{f}}\right)$, the diameter of the drain $(D)$, thickness of filter $(t)$, water level above the bedrock $(H)$ and drain elevation from bedrock to middle of drain $(Y)$. The simulation model and its hydraulic properties of the canal are given in Table 1 . To account for the variation of properties, 75 runs had to be completed.

The finite element discretization is presented in Fig. 4. Quadrilateral and triangular elements are defined in the region of the drain and canal. The total number of elements was 65,700 .

The specification of the boundary conditions is a key step in the FE method. The boundary conditions are, in essence, the driving force for the groundwater. The total hydraulic head is made up of pressure head and elevation, and it is the primary unknown. As a consequence of the high permeability, the pore pressure $(P)$ on a seepage face is zero. Setting the $P=0$ condition requires care, however. It is possible for this location to inadvertently become a source of water.

Table 1 Physical and hydraulic properties of the simulation model

\begin{tabular}{lll}
\hline Parameter & $\begin{array}{l}\text { Symbol of } \\
\text { parameter }\end{array}$ & Value \\
\hline Diameter of drain (m) & $D$ & $0.1,0.2$ \\
Thickness of filter (m) & $t$ & $0.2,0.25,0.3$ \\
Water level above the bedrock (m) & $H$ & $20.5,20.8,21.2$ \\
Drain elevation from bedrock to mid- & $Y$ & $18.5,19,19.5$ \\
$\quad$ dle of drain (m) & & \\
Hydraulic conductivity of soil $(\mathrm{m} / \mathrm{s})$ & $k_{\mathrm{s}}$ & $10^{-5}$ \\
Hydraulic conductivity of filter $(\mathrm{m} / \mathrm{s})$ & $k_{\mathrm{f}}$ & $10^{-3}$ \\
\hline
\end{tabular}

Fig. 3 Cross section of solution domain

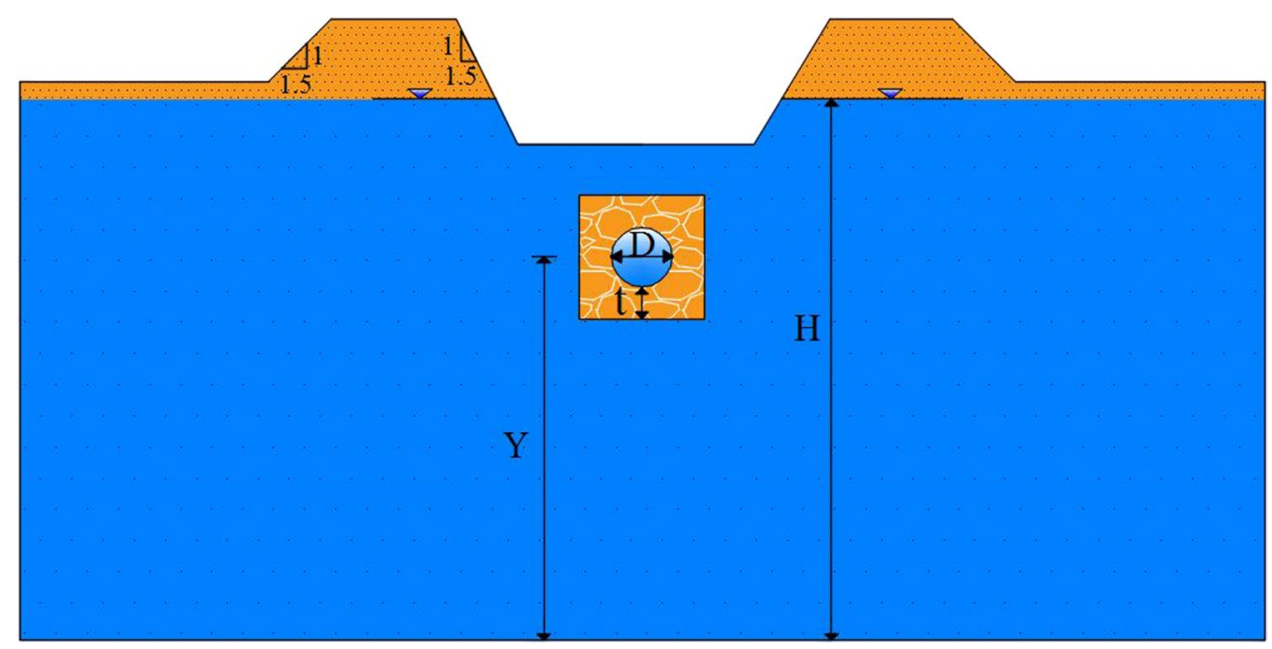


Fig. 4 Generated mesh around drain and filter

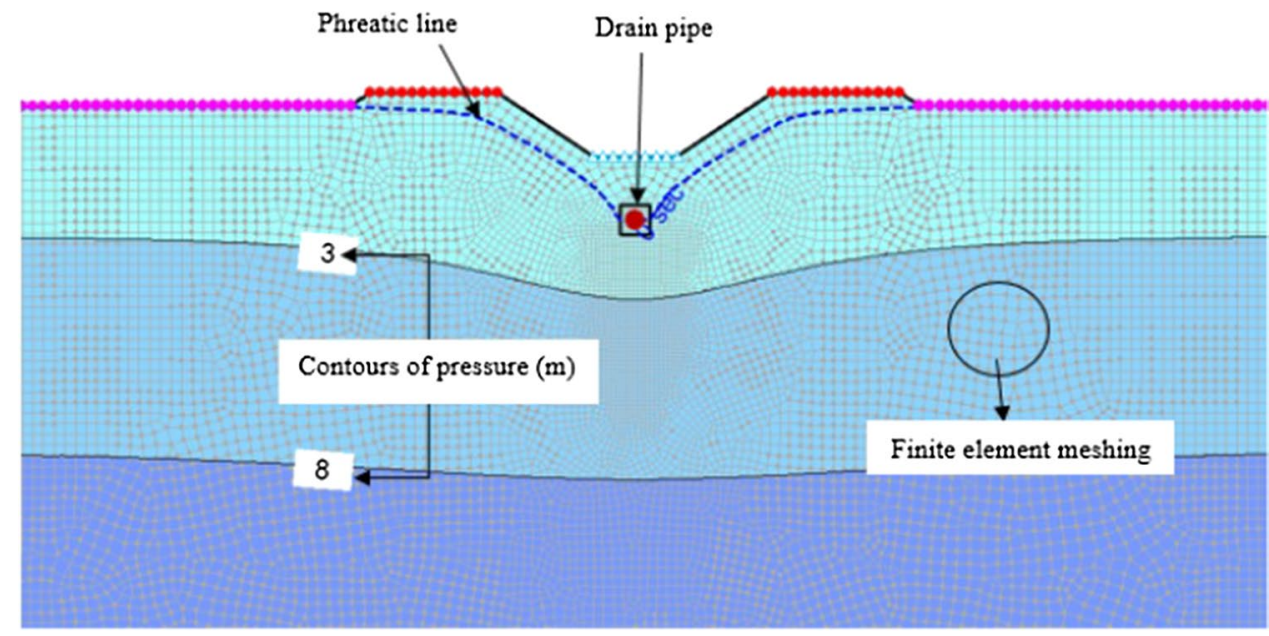

Boundary conditions for groundwater heads were defined in terms of total head $(H)$ for the following drainage arrangement $(Y=18.5,19$, and $19.5 \mathrm{~m})$. The bed and side walls were treated as impermeable boundaries. Boundary conditions for drain pipes were zero pressure (free drainage).

\section{Regression analysis}

Regression analysis is used to quantify a correlation between independent variables and the dependent variable. Here, an attempt to quantify the partially drained pressure head, $P$, is performed. The pressure heads on the bed of a canal, in the middle of the canal, and over the drain were obtained. It is assumed that linear and nonlinear relationships exist between $P$ and the independent parameters; the regression function can be written in a general form as:

$$
P=f(t, D, H, Y)
$$

Fig. 5 a Seepage lines without a drain and filter with $H=20.8 \mathrm{~m}$, b flow vectors for a canal without a drain and filter $H=20.8 \mathrm{~m}$, c seepage lines with a drain and filter for $H=20.8 \mathrm{~m}, Y=21.5 \mathrm{~m}$, $D=0.2 \mathrm{~m}$ and $t=0.25 \mathrm{~m}$
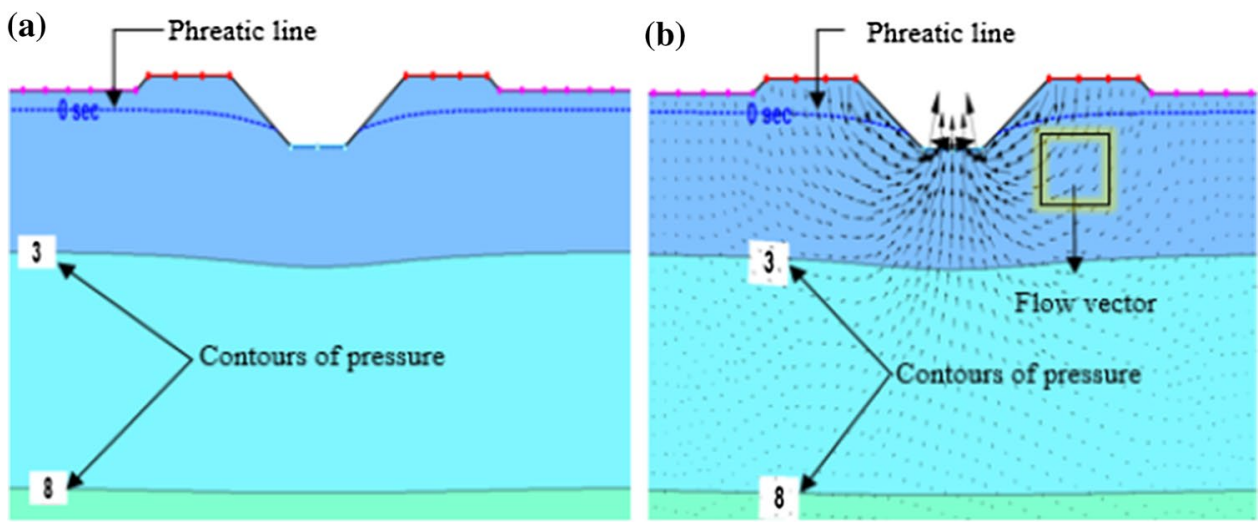

(c)

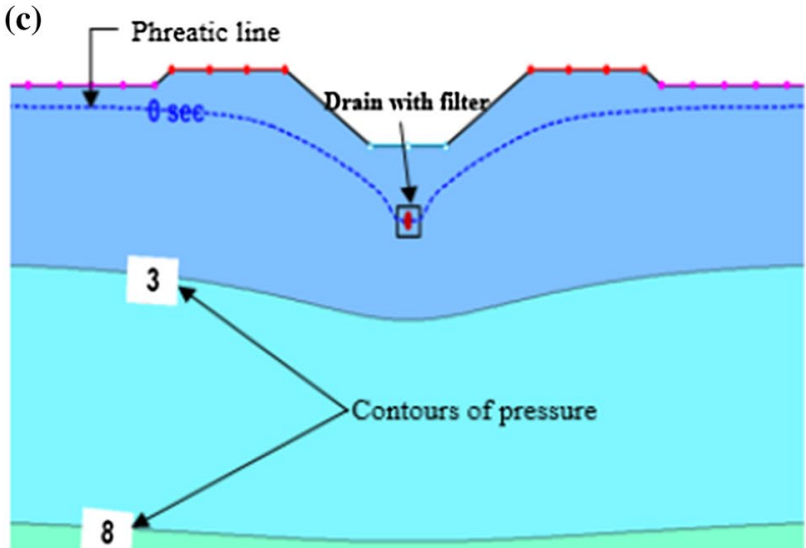


In addition, the dimensionless function between independent parameter $\left(P_{t} / P_{0}\right)$ and independent parameters $(D / t, Y / H)$ can be written in a general form as Eq. (7):

$\frac{P_{t}}{P_{0}}=f_{1}\left(\frac{D}{t}, \frac{Y}{H}\right)$
Fig. 6 a Phreatic lines and flow lines for $H=20.8 \mathrm{~m}$ without drain pipe, $\mathbf{b}$ flow lines with a drain for $H=20.8 \mathrm{~m}, Y=19 \mathrm{~m}$, $D=0.2 \mathrm{~m}$, c phreatic lines for different drain diameters $(D=0.1,0.2 \mathrm{~m})$ with $H=20.8 \mathrm{~m}, Y=19 \mathrm{~m}$ where $P_{t}$ is the pressure head under the canal with drain installation and $P_{0}$ is the pressure head without drain effect under the canal.

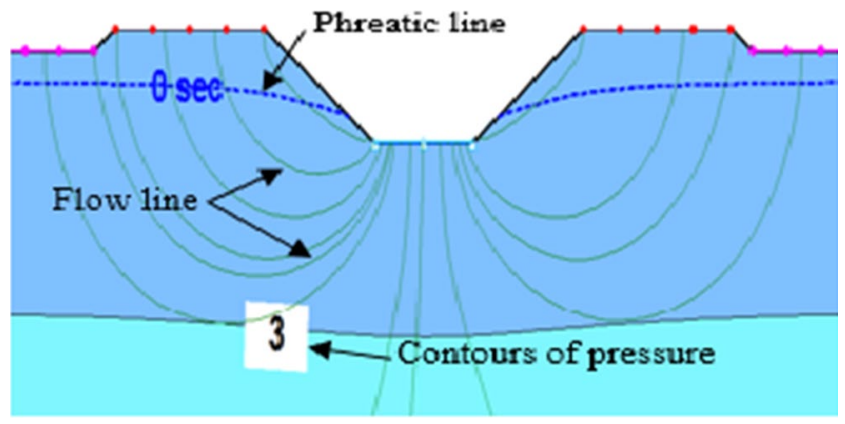

(a) Phreatic and flow lines without drain pipe for condition $H=20.8 \mathrm{~m}$

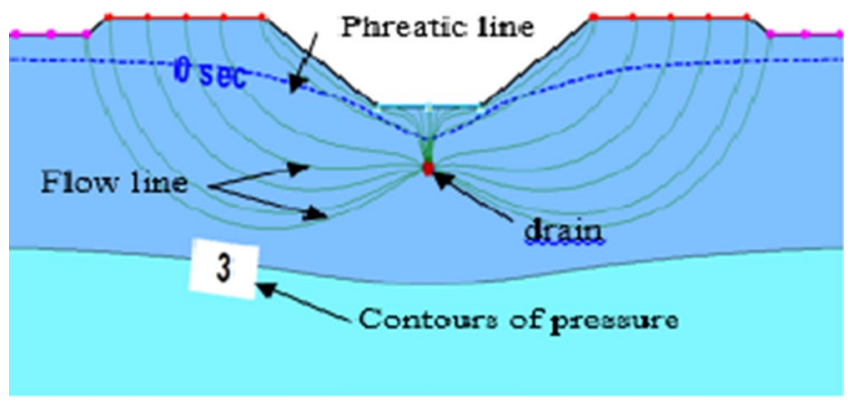

(b) Phreatic and flow lines with drain pipe under the canal bottom for condition $H=20.8 \mathrm{~m}$, $Y=19 \mathrm{~m}$ and $D=0.2 \mathrm{~m}$

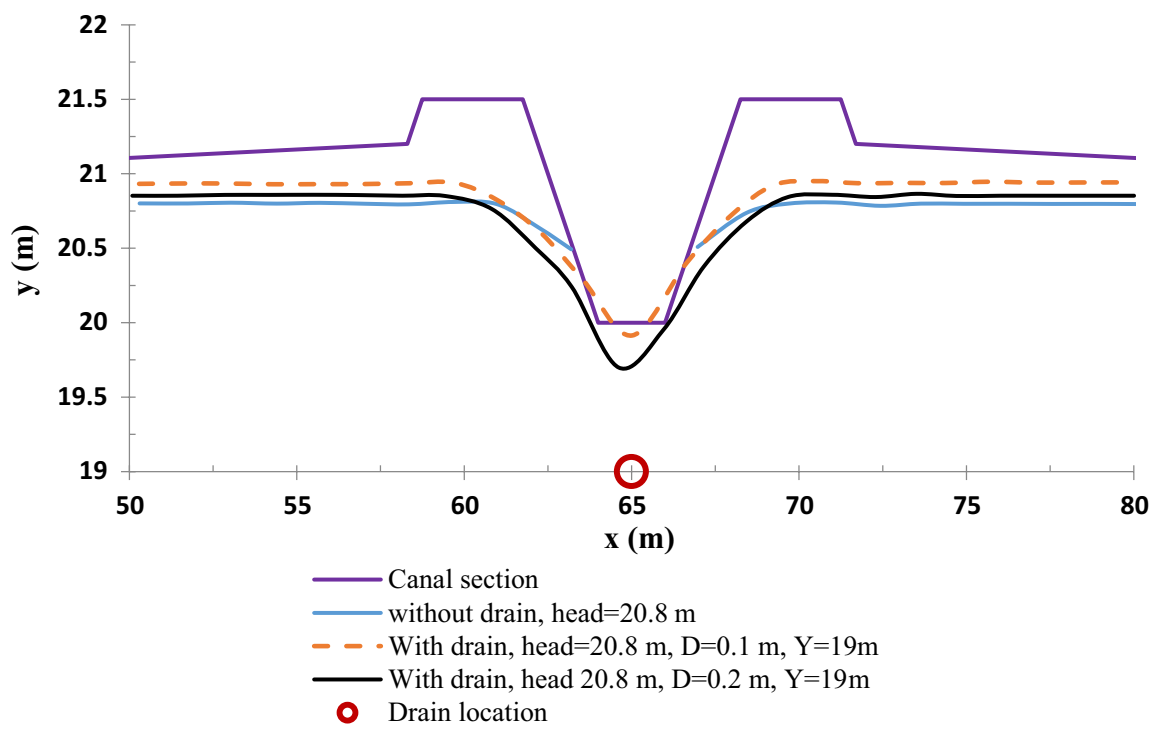

(c) Comparison of the phreatic lines with and without drain pipe for condition $H=20.8 \mathrm{~m}$, $Y=19 \mathrm{~m}$ 
Fig. 7 Phreatic lines for different drain depths from the canal bed with $H=20.5 \mathrm{~m}$ and $D=0.2 \mathrm{~m}$

Fig. 8 Phreatic lines for different thicknesses of filter with $H=20.8 \mathrm{~m}, D=0.2 \mathrm{~m}$, $Y=18.5 \mathrm{~m}$
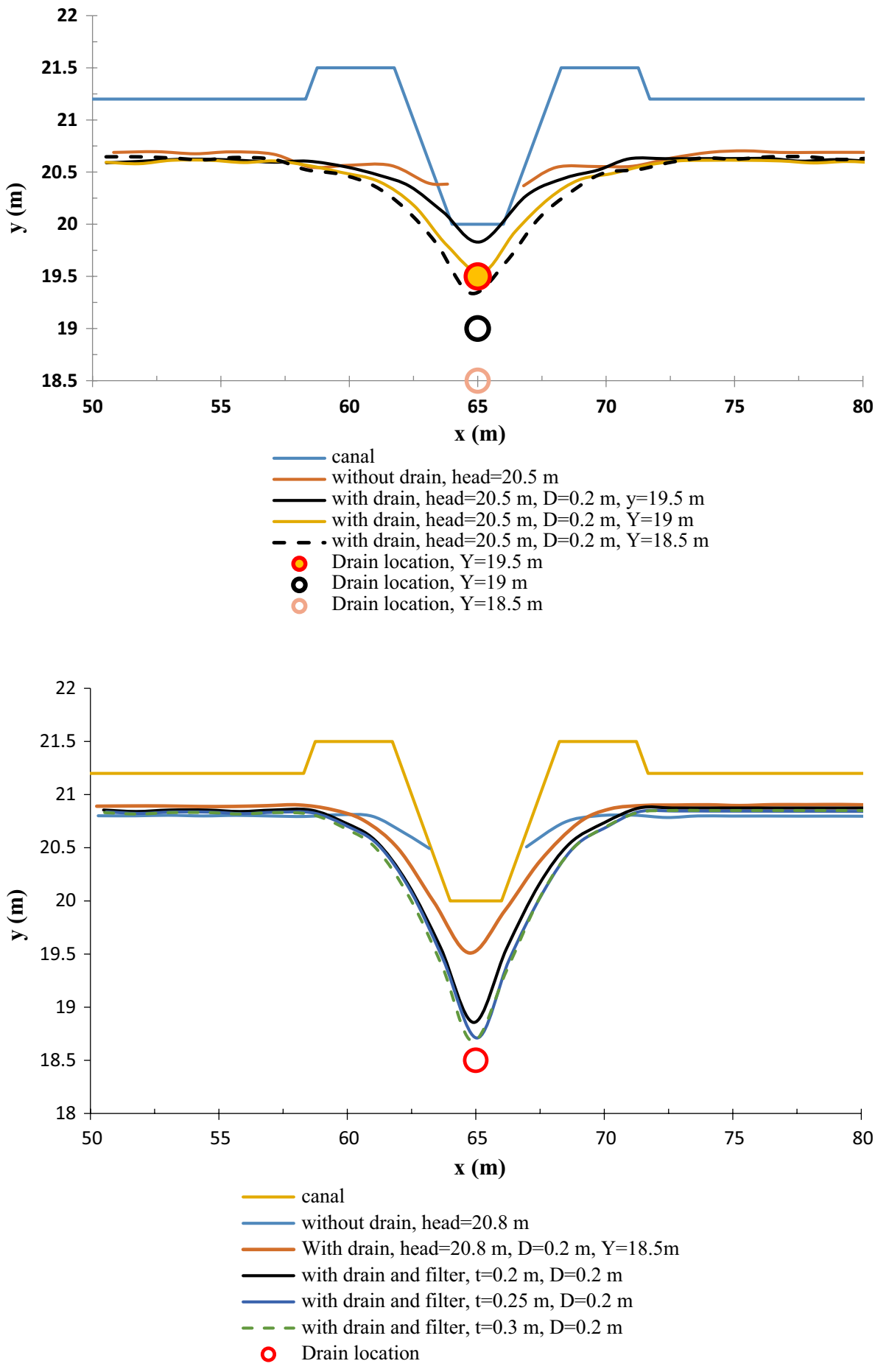

\section{Results and discussion}

\section{Finite element (FE) analyses}

In many irrigation projects where the groundwater table is high, part of the canal may be located below the water table. In such cases, the groundwater would apply uplift pressure to the bottom and side panels of the lining. As noted earlier, this phenomenon may cause deformation, displacement or rupture of the concrete panels, or other damage. This leads to high maintenance costs and lowered performance. The canal model with the drain was used to simulate the performance of horizontal drainage systems to intercept the seepage losses, to prevent waterlogging, and consequently to reduce these concerns. 
Fig. 9 Hydraulic gradients for differing head values

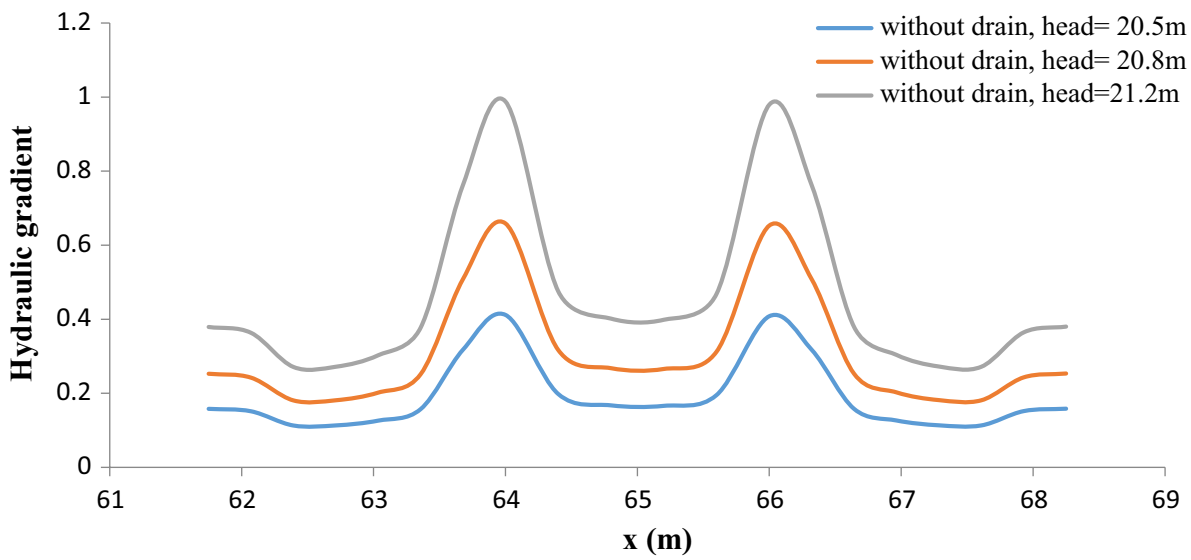

Fig. 10 Hydraulic gradients for different drain depths with $D=0.1 \mathrm{~m}, H=20.5 \mathrm{~m}$
Fig. 11 Gradient for different filter thicknesses around drain with $D=0.2 \mathrm{~m}, Y=18.5 \mathrm{~m}$, $H=20.8 \mathrm{~m}$
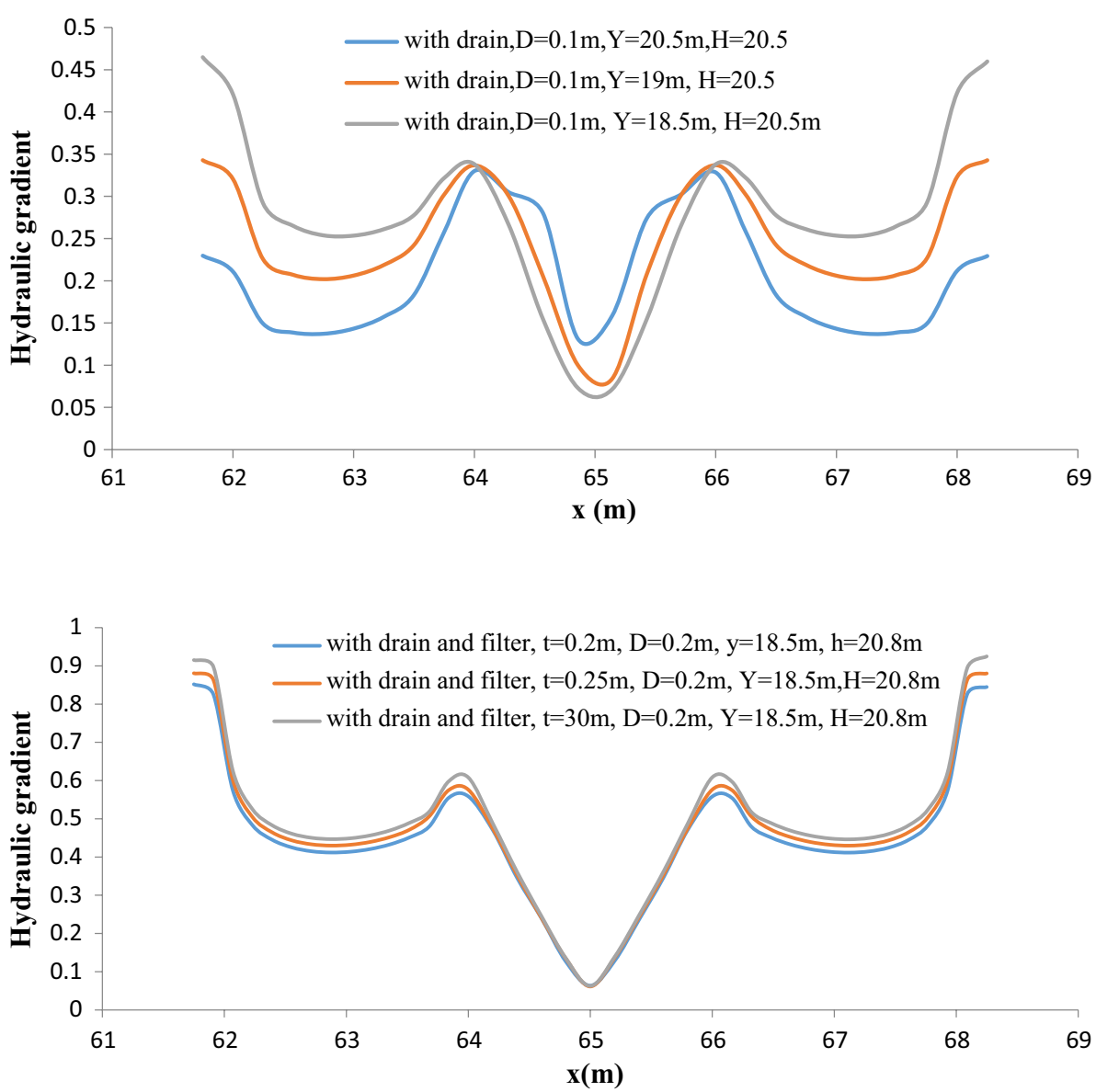

The phreatic line is defined by a zero-pressure condition. The groundwater heads in the presence of a subsurface drain for various water tables are shown in Fig. 5 . The seepage lines with no drainage system provided for $H=20.8 \mathrm{~m}$ are shown in Fig. 5a. It can be seen that the seepage curves intersect the canal lining at this head. This means that the seepage discharge is high, and the soil is not capable of draining the water safely. Excess hydrostatic pressure exists on the canal at both the bottom and the side walls. In Fig. 5b, the flow vectors indicate there is still some seepage out of the soil and into the canal. In this condition, the use of a filter drain system under the canal becomes necessary. As shown in Fig. 5c for $H=20.8 \mathrm{~m}$, $Y=18.5 \mathrm{~m}, D=0.2 \mathrm{~m}$, and $t=0.25 \mathrm{~m}$, with a filter drain, the seepage lines are located below the canal bottom. Therefore, no uplift is imposed on the canal lining, and the drainage system is able to discharge the excess water safely from the bottom of the lining. 
(a)

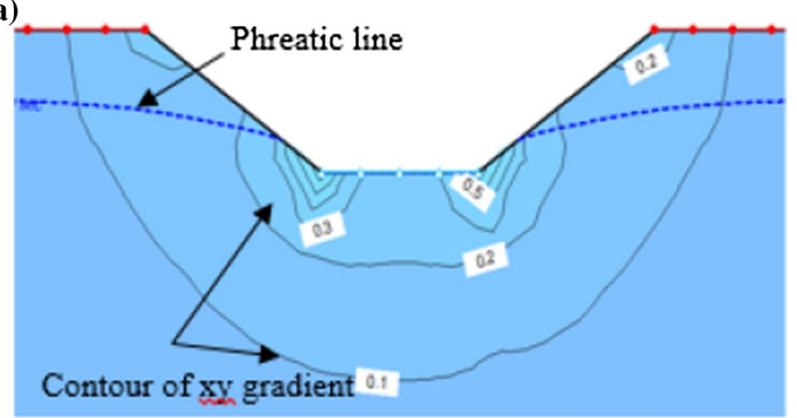

(b)

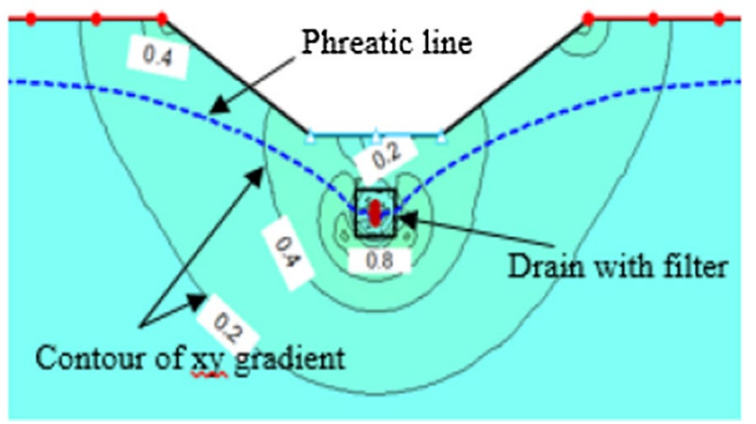

Fig. 12 Contours of hydraulic gradient $\mathbf{a}$ without a drain and filter, $H=20.8 \mathrm{~m}$, b with a drain and filter, $H=20.8 \mathrm{~m}, D=0.2 \mathrm{~m}$, $\mathrm{Y}=19 \mathrm{~m}, t=0.25 \mathrm{~m}$

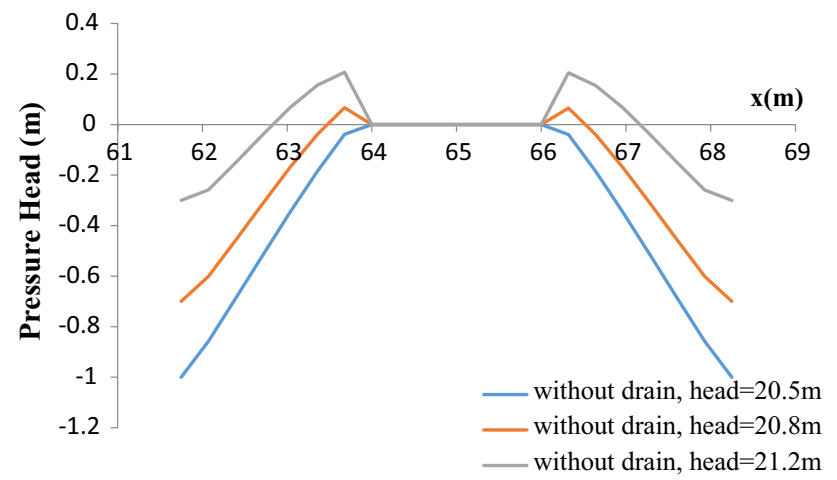

Fig. 13 Uplift forces for different water head values

The water movement in a subterranean agricultural drainage system is related to the drain diameter. Tests were carried out on different diameter drains to assess the impact of the diameter on phreatic and flow lines. Comparisons shown in Fig. 6a, b effectively demonstrate that pore water pressure in soil is reduced and the phreatic surface is lowered below the canal lining. This improves the stability of canal system and reduces the already discussed uplift issues.

It is observed in Fig. 6a-c that with a constant depth drain, the piezometer surface is lowered as the drain diameter increases. Therefore, bigger diameters are preferred for the drain pipes where the uplift forces must be reduced.
Next, the effect of drain depth is studied. Drain pipe installations depend on groundwater elevation, drain pipe diameter, and thickness of the canal lining. The canal must be able to resist pore pressure; thus, the lining thickness must be sufficient for this task. For this purpose, drains with canal bed depths of $0.5,0.8$, and $1.2 \mathrm{~m}$ are simulated. As shown in Fig. 7, for a constant drain diameter, increasing drain depth from the canal bed results in a reduction in groundwater head. It is obvious that deeper installations of drains are more expensive, so a balance of cost and performance should be considered in practice.

The position of the phreatic line at the end of the analysis for water surface $0.8 \mathrm{~m}$ above the canal bed, filter thicknesses of $0.2,0.25$, and $0.3 \mathrm{~m}$, and with a drain with the diameter of $0.2 \mathrm{~m}$ located $1.5 \mathrm{~m}$ below of the canal bed is shown in Fig. 8.

Soils transport water under both saturated and unsaturated conditions. When a soil is saturated, the pores are filled with water. As pore water pressures decrease, more pores become air-filled and the hydraulic conductivity is reduced. A significant difference in the phreatic lines can be observed as the filter thickness is varied, and the results are shown in Fig. 8. However, increasing thicknesses of the filter with increasing depth of drain under the canal bed will decrease water table surface. The simulation results also indicate that increasing the filter thickness with increasing drain diameter and depth drain of bed canal can decrease the water table surface and uplift force.

Cracked canal lining failures are often caused by uplift pressure forces exerted by groundwater rising above the canal bed during periods of low flow or no flow through the canal. Figure 9 shows results of hydraulic gradient versus distance with different water levels in the canal. It is seen that there is enough information for obtaining one solution. Notably, there are only three model runs carried out for the canals without drain pipes to calculate hydraulic gradient. It can be seen that for all cases, a maximum hydraulic gradient is in the corner of the canal. When water level is high, the hydraulic gradient is approximately 1 . This situation may be critical and cause disruption in the canal.

These computational models include the pipe drains under the canal bed with a range of drain depth. In Fig. 10, a drain with $0.1 \mathrm{~m}$ diameter is made at different locations. Water flows through the permeable soil in a steady manner from the field to the drain. The deepest drain has maximum gradient value at the side of the canal and a minimum gradient value at the bottom of canal. Also, a large drain diameter has maximum gradient at the side of canal. So, the drain is filled with water and is maintained at a constant water level far away the canal.

Conditions for groundwater heads were quantified in terms of pressure head for each case of drainage arrangement above the canal bed. The side walls were considered

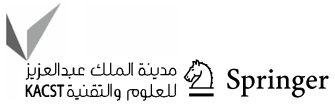


Fig. 14 Hydrostatic pressures on a canal $\mathbf{a}$ with a drain and filter, $H=20.5 \mathrm{~m}, Y=19.5 \mathrm{~m}$, b with a drain and filter, $H=21.2 \mathrm{~m}, Y=18.5 \mathrm{~m}$

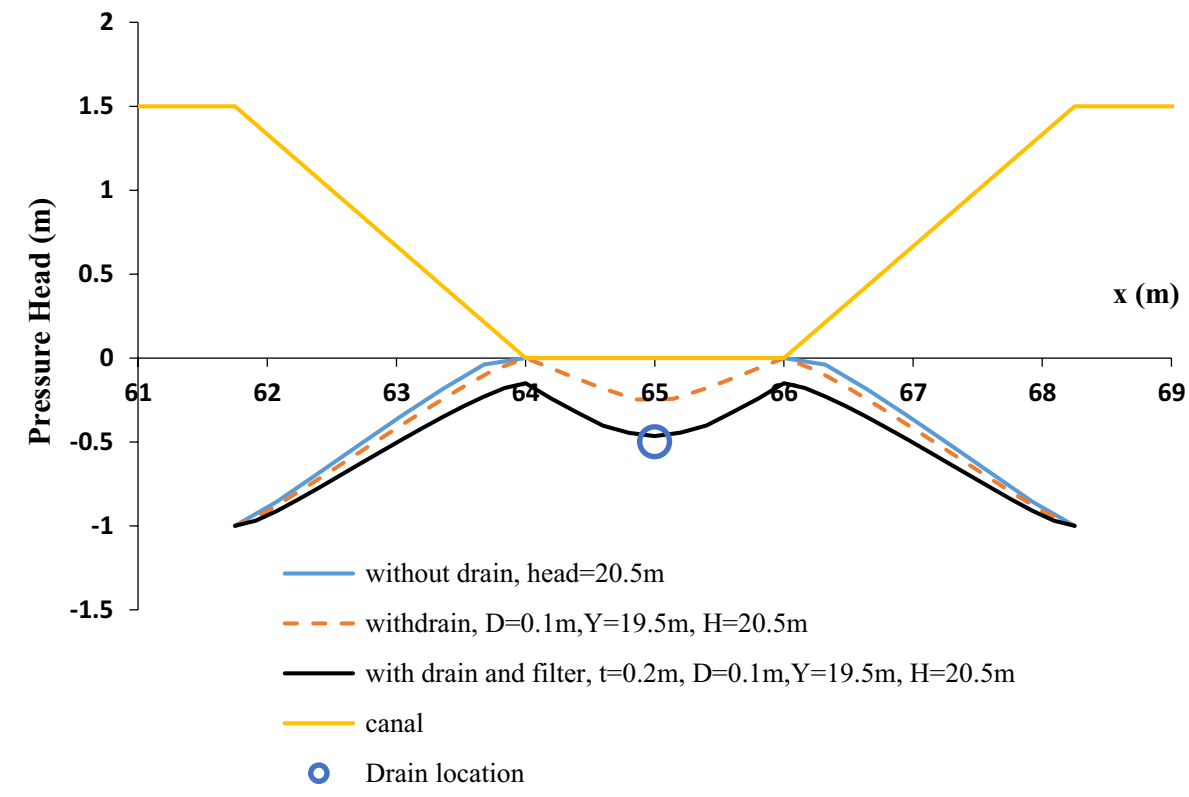

(a) with a drain and filter, $H=20.5 \mathrm{~m}, Y=19.5 \mathrm{~m}$

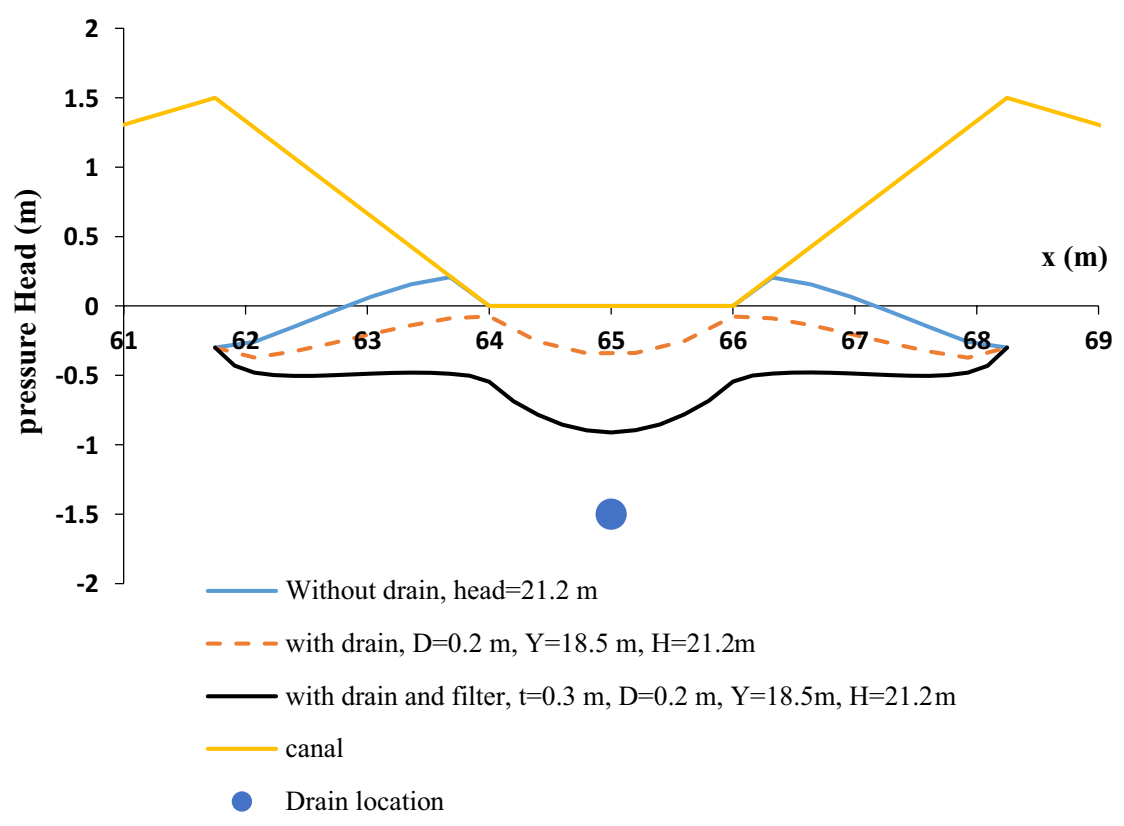

(b) with a drain and filter, $H=21.2 \mathrm{~m}, Y=18.5 \mathrm{~m}$ as rigid or impervious boundaries. Gradients are calculated for three different filter thicknesses, and the results from numerical modeling are shown in Fig. 11. It is seen that the gradient along the cross section of canal with different filter thicknesses around drain is almost same and the difference among the gradients is negligible.

Different drain diameters and filter thicknesses can affect the water surface level. This issue is presented in exemplifying figures (Fig. 12a, b). As seen there, the design given by drain pipes positioned below the canal bottom results in maximum gradients near the drain. In a canal without a drain, the hydraulic gradient in the corner of the canal bed is large and could cause disruption at that location.

Pressure head varies with distance from the canal. Below the canal bed, the negative pressure head is limited to a pressure distribution such as that shown in Fig. 13. For locations below the water table, the hydrostatic pressure increases with depth. An initial water table may give an accurate pore water pressure when the water table is horizontal. However, if the water table is curved, this option only approximates the actual initial conditions. For sufficiently high groundwater head, the soil pressure can cause soil layers to fail. At the 
(a)

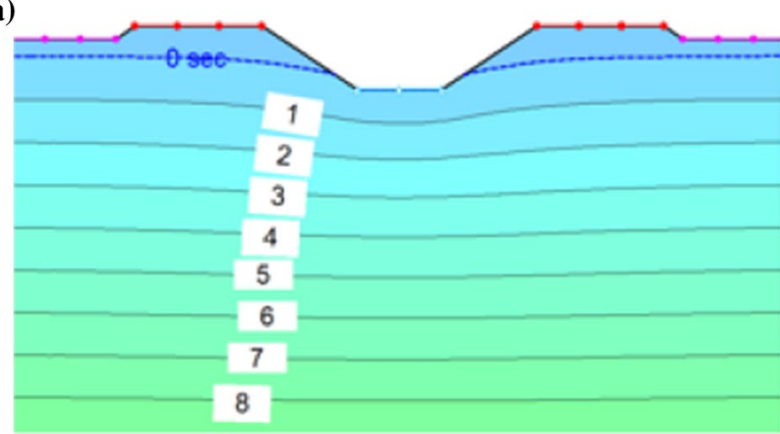

(b)

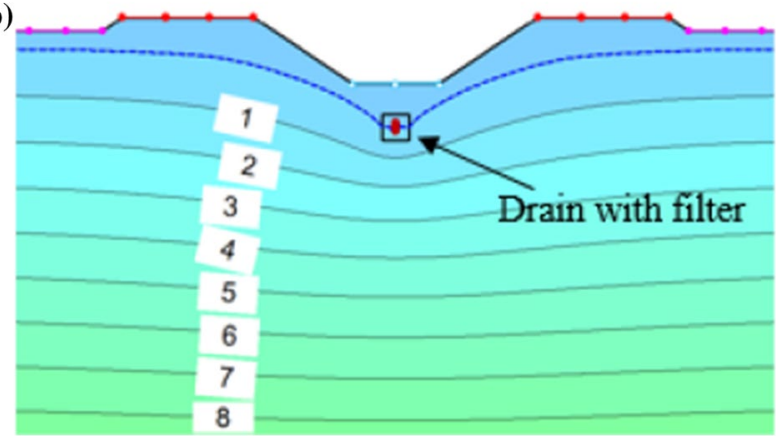

Fig. 15 Pressure contours a without drain pipes, $H=20.8 \mathrm{~m}$, b with a drain and filter, $t=0.25 \mathrm{~m}, D=0.2 \mathrm{~m}, Y=19 \mathrm{~m}, H=20.8 \mathrm{~m}$

occurrence of failure, the total stress in the soil becomes equal to the water pressure and the effective stress becomes zero.

When a canal is positioned at a depth coincident with the phreatic surface of groundwater, the potential adverse effects upon the water containment facility must be accounted for. If the water pressure is sufficiently high and is able to lift the soil layer, hydrostatic uplift occurs. Among the failure mechanisms is roofing, boiling, or heaving with a large blister. Figure 14 shows a drain and filter under a bed canal where the uplift pressure is reduced. Filters employed around the drains are effective at decreasing the hydrostatic pressure. The negative uplift forces in Fig. 14 designate that the groundwater elevation is below the canal bottom and there is no pressure from groundwater on the canal lining.

If the maximum calculated uplift force is calculated based on the maximum measured piezometer head, then the soil layer resistance calculations can be considered conservative.

Modeling runs were carried out both for the situation with no drainage (Fig. 15a) and for a case with drainage (Fig. 15b). Pressure contours in the porous soil media in the vicinity of the canal are shown in the figures. The phreatic line is horizontal and above the canal bed. Other contours of pressure lines are seen to be horizontal. Below the phreatic line, pore pressure is positive. In general, the use of a drain with a filter lowers the phreatic surface and reduces pressure, especially near the drain pipes.

Figure 16 shows the configuration of the drain under the canal bed with groundwater level of $0.8 \mathrm{~m}$ above it. The drain is $1 \mathrm{~m}$ from the canal bed. The performance of a drain pipe and a drain with filter is compared with the no-drain scenario. If piezometers are placed at different locations along an equipotential line, the water level will rise to the same at all locations.

A decline in the phreatic line (dashed blue line) in Fig. 16b demonstrates the positive effect of drain pipe in reduction in groundwater water level reduction (comparison of Fig. 16a with b). In addition, comparison of Fig. 16b, c denotes that using filter around the drain could reduce phreatic line much more and it can be noted that application of filter reduces soil particles migration in downstream direction too. This reduces piping/undermining phenomenon.

\section{Regression analysis pressure head}

The pressure head $(m)$ under the canal bed including drain pipe is a function of filter thickness $(t)$, drain diameter $(D)$, drain elevation $(Y)$ and depth of groundwater surface $(H)$. Considering these four independent parameters, linear and nonlinear equations for pressure head with SPSS software are evaluated in Eqs. 8-10. Equation 8 is linear and Eqs. 9 and 10 are nonlinear. Determination coefficients and RMSE for these equations are presented in Table 2. It is seen that the value of RMSE for Eq. 8 is nearer to zero than other equations. So, this equation is most appropriate for predicted pressure head.

$P=-12.06-0.9(t)+0.23(D)+0.124(H)+0.472(Y)$

$P=19.3+138.34(t)^{26.38}+198.72(D)^{116.64}$

$$
+0.01(H)^{1.655}-58.52(Y)^{-0.34}
$$

$P=-4.065 \times 10^{9}(t)^{0.307}(D)^{-0.046}(H)^{1.976}(Y)^{-9.56}$

The dimensionless linear and nonlinear Eqs. 11-13 are calculated for the total pressure head under the channel. Values of $P_{t}$ and $P_{0}$ are total pressure head under the channel in the presence of a drain pipe and without a drain, respectively. The independent parameters are $D / t$ and $Y / H$.

$\frac{P_{t}}{P_{0}}=0.015\left(\frac{D}{t}\right)+0.261\left(\frac{Y}{H}\right)+0.733$

$\frac{P_{t}}{P_{0}}=0.736+0.133\left(\frac{D}{t}\right)^{0.074}+0.141\left(\frac{Y}{H}\right)^{2.029}$

$\frac{P_{t}}{P_{0}}=1.008\left(\frac{D}{t}\right)^{0.01}\left(\frac{Y}{H}\right)^{0.243}$ 
Fig. 16 Potential contour lines in simulated models a without a drain and filter $H=20.8 \mathrm{~m}$, b with a drain, $D=0.2 \mathrm{~m}$, $Y=19 \mathrm{~m}, H=20.8 \mathrm{~m}, \mathbf{c}$ with a drain and filter, $D=0.2 \mathrm{~m}$, $Y=19 \mathrm{~m}, H=20.8 \mathrm{~m}, t=0.25 \mathrm{~m}$

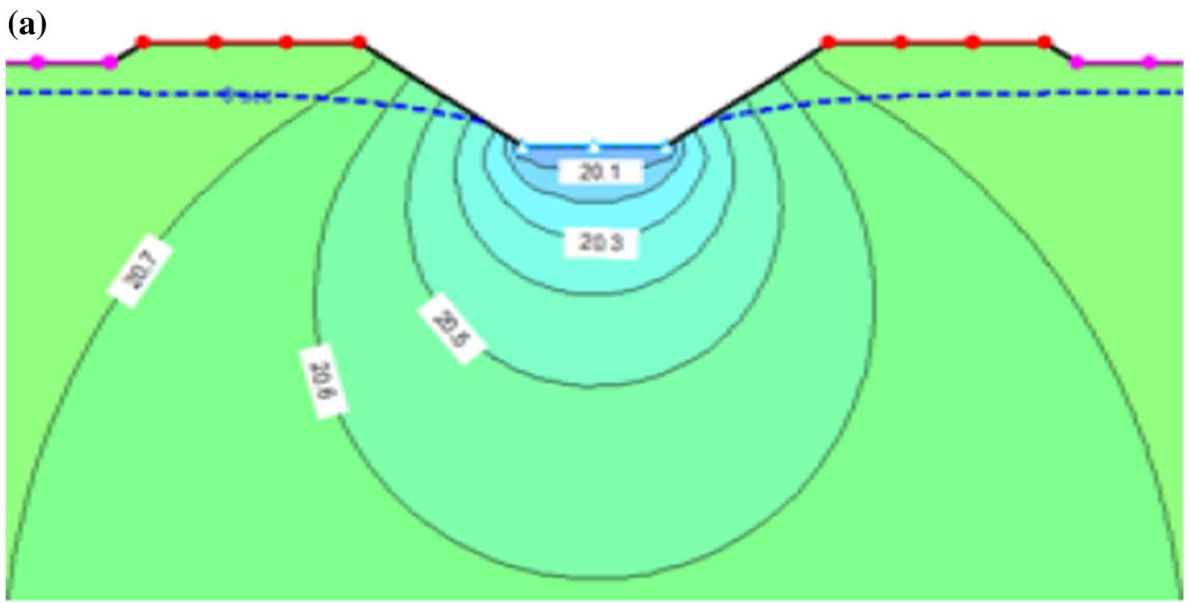

(b)
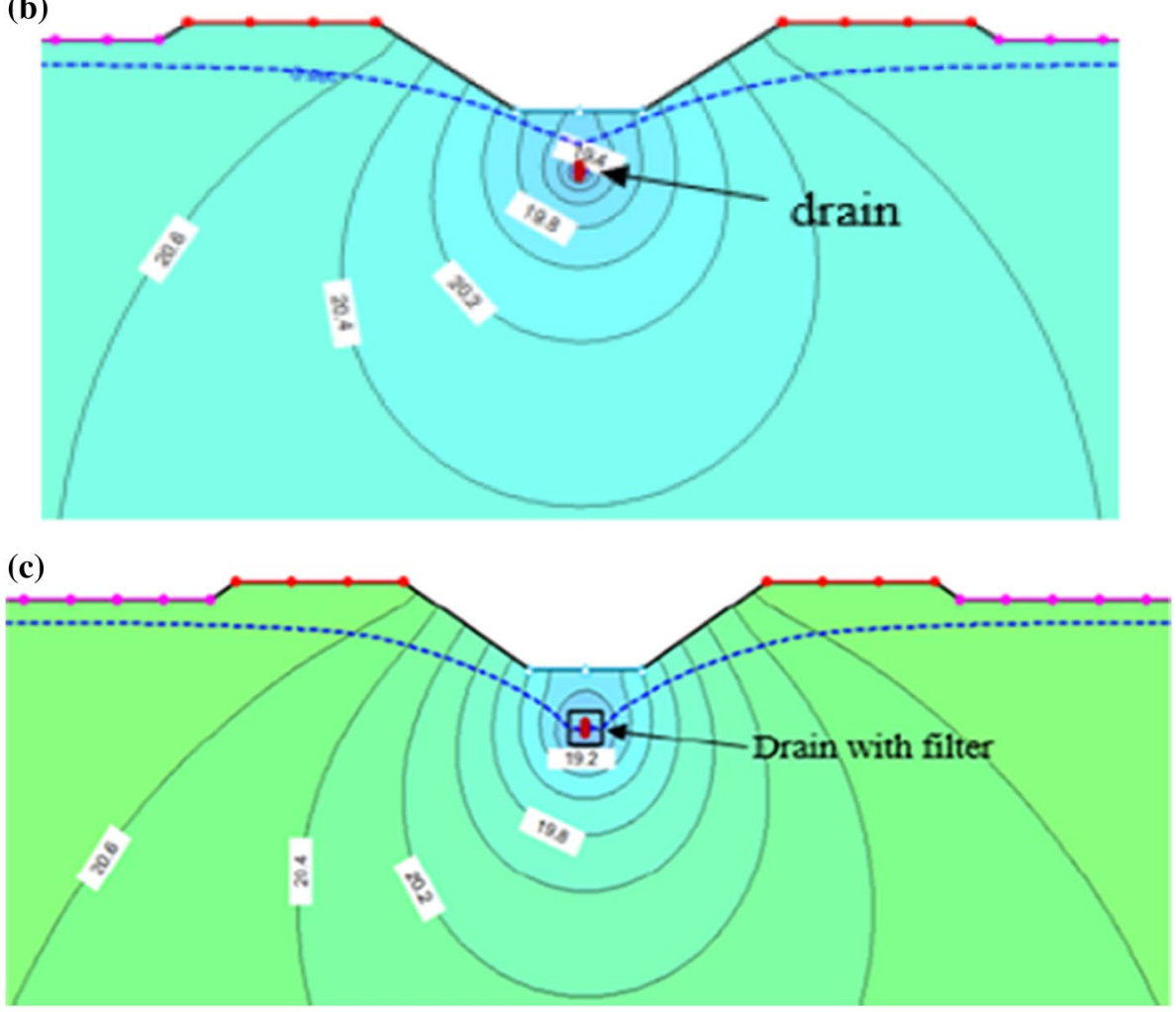

Table 2 Linear and nonlinear regression results for pressure head $(P$ or $\left.P_{t} / P_{0}\right)$

\begin{tabular}{llll}
\hline Models & Model type & $R^{2}$ & RMSE \\
\hline Equation 8 & Linear & 0.950 & 0.048 \\
Equation 9 & Nonlinear 1 & 0.883 & 0.079 \\
Equation 10 & Nonlinear 2 & 0.804 & 0.091 \\
Equation 11 & Linear (dimensionless) & 0.907 & 0.0023 \\
Equation 12 & Nonlinear 1 (dimensionless) & 0.911 & 0.0022 \\
Equation 13 & Nonlinear 2 (dimensionless) & 0.91 & 0.0023 \\
\hline
\end{tabular}

Based on the results given in Table 2, all three dimensionless equations have better performance compared to Eqs. 7-9. Among them, Eq. 11 is the most accurate with $R^{2}=0.911$ and $\mathrm{RMSE}=0.0022$.

Figure $17 \mathrm{a}-\mathrm{c}$ presents the relationships between pressure head obtained with SEEP/W (2012) and that predicted by the regression equations. The data analysis was carried out using SPSS software, and the results indicate that it is possible to articulate reasonable fits between the modeled 
(a)

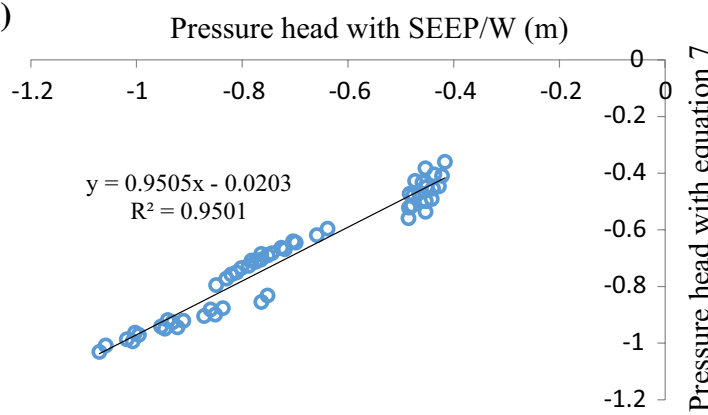

(b)

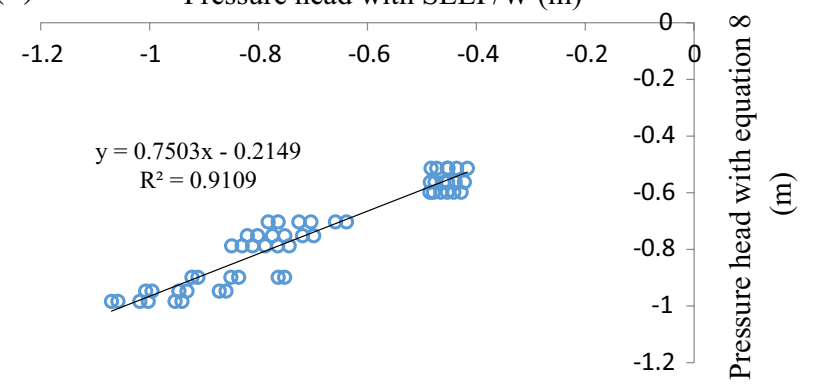

(c) Pressure head with SEEP/W (m)

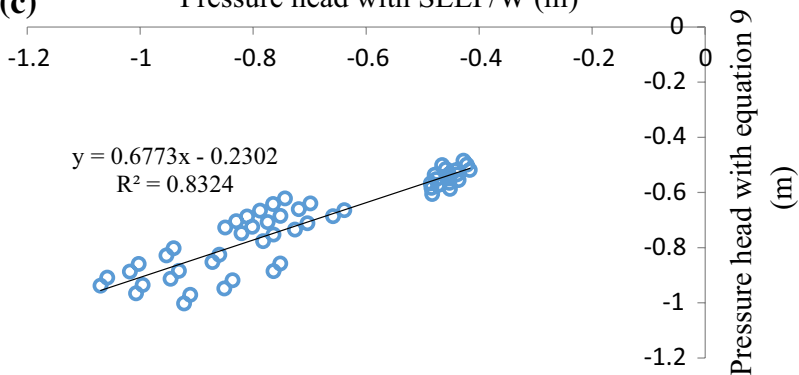

Fig. 17 Variation pressure head (numerical simulation) versus pressure head (regression equation) for a Eq. 8, b Eq. 9, c Eq. 10 and predicted pressure heads. As the figure shows, the pressure head is negative because the phreatic line is located under the bed of canal and lower than the drain. The region between the canal and drain is unsaturated. Equation 8 is preferable as its performance parameter $\left(R^{2}\right)$ is quite similar to that of model of SEEP/W (2012) and as it is linear so that its implementation is simple. Equation 10 is considered appropriate for an estimation, but more reliable models are often needed.

\section{Application example}

The knowledge of the uplift pressure at the canal bottom allows us to evaluate methods to prevent a canal lining from cracking. These methods comprise increasing canal lining thickness, use of a weep hole in the canal invert, or installation of a drain pipe with envelop under the canal bed. An example is used to demonstrate the application of the method. Consider a situation where the groundwater table above the canal bed $(h)$ is assumed to be $0.5 \mathrm{~m}$, i.e., $H=20.5 \mathrm{~m}$. Without any drain pipe under the canal bed, the hydrostatic pressure from groundwater in the middle of the canal bed will be $P=0.5 \mathrm{~m}$ or $p=4.91 \mathrm{kN} / \mathrm{m}^{2}$. Under this condition, the canal lining thickness/material should be checked for cracking.

Another solution is the installation of a drainpipe under the canal bed. In the second example, with the above same groundwater table, and with a drain pipe located under the canal bed with at a depth $=0.3 \mathrm{~m}$ under the canal invert, i.e., $y=0.3 \mathrm{~m}$ or in this example $Y=19.7 \mathrm{~m}$. If the drain pipe diameter is $0.1 \mathrm{~m}$ with a lining (envelop thickness) $t=0.2 \mathrm{~m}$, application of Eq. 12 yields $P=-0.38 \mathrm{~m}$ or $p=-3.69 \mathrm{kN} /$ $\mathrm{m}^{2}$. In this example, $P$ is negative which signifies suction in the soil that is not dangerous for canal lining cracks. In fact,
Table 3 Effect of hydraulic parameters on uplift pressure under the canal invert

\begin{tabular}{lllllllr}
\hline$H(\mathrm{~m})$ & $h(\mathrm{~m})$ & $Y(\mathrm{~m})$ & $y(\mathrm{~m})$ & $D(\mathrm{~m})$ & $t(\mathrm{~m})$ & $P(\mathrm{~m})$ & $p\left(\mathrm{kN} / \mathrm{m}^{2}\right)$ \\
\hline 20.5 & 0.5 & 0 & 0 & 0 & 0 & 0.50 & 4.91 \\
20.5 & 0.5 & 19.7 & 0.3 & 0.1 & 0.2 & -0.38 & -3.69 \\
20.6 & 0.6 & 19.7 & 0.3 & 0.1 & 0.2 & -0.36 & -3.57 \\
20.7 & 0.7 & 19.7 & 0.3 & 0.1 & 0.2 & -0.35 & -3.45 \\
20.8 & 0.8 & 19.7 & 0.3 & 0.1 & 0.2 & -0.34 & -3.33 \\
20.9 & 0.9 & 19.7 & 0.3 & 0.1 & 0.2 & -0.33 & -3.21 \\
21 & 1 & 19.7 & 0.3 & 0.1 & 0.2 & -0.31 & -3.09 \\
21.1 & 1.1 & 19.7 & 0.3 & 0.1 & 0.2 & -0.30 & -2.96 \\
21.2 & 1.2 & 19.7 & 0.3 & 0.1 & 0.2 & -0.29 & -2.84 \\
21.3 & 1.3 & 19.7 & 0.3 & 0.1 & 0.2 & -0.28 & -2.72 \\
21.4 & 1.4 & 19.7 & 0.3 & 0.1 & 0.2 & -0.27 & -2.60 \\
21.5 & 1.5 & 19.7 & 0.3 & 0.1 & 0.2 & -0.25 & -2.48 \\
\hline
\end{tabular}


a drainpipe with envelope reduces pore water pressure in the soil from 4.91 to $-3.69 \mathrm{kN} / \mathrm{m}^{2}$. If $h$ is increased from 0.5 to $1.5 \mathrm{~m}, P$ increases but it remains negative. More solved examples are presented in Table 3.

\section{Conclusion}

The most effective way to control the uplift pressure is to provide a filter drainage system under the canal lining. Based on the overall results of the numerical investigation, the following conclusions can be drawn.

- With a filter drain, the seepage lines are located beneath the canal bottom. Therefore, no uplift is imposed on the canal lining, and the drainage system is able to discharge the excess water safely from the bottom of the lining.

- When the flow lines are conducted to a large drain diameter, the piezometer surface is located lower than when a small-diameter drain is used.

- For constant drain diameters, increasing the drain depth below of the canal bed will reduce the groundwater head.

- Increasing the thickness of the filter with increasing depth of drain decreases water table surface.

- Simulation results indicate the increasing thickness of filter with increasing drain diameter and depth of drain decreases the water table surface and uplift force.

- When the water level is high, the hydraulic gradient is near to 1 . This situation may be critical and caused disrupt canal.

- Filters around the drain are effective at decreasing the hydrostatic pressure.

- Linear equations provide better agreements between predicted and observed values.

\section{Compliance with ethical standards}

Conflict of interest On behalf of all authors, the corresponding author states that there is no conflict of interest.

Open Access This article is distributed under the terms of the Creative Commons Attribution 4.0 International License (http://creativeco mmons.org/licenses/by/4.0/), which permits unrestricted use, distribution, and reproduction in any medium, provided you give appropriate credit to the original author(s) and the source, provide a link to the Creative Commons license, and indicate if changes were made.

\section{References}

Ayars J, Christen E, Hornbuckle J (2006) Controlled drainage for improved water management in arid regions irrigated agriculture. Agric Water Manag 86:128-139. https://doi.org/10.1016/j.agwat .2006 .07 .004
Bucur D, Savu P (2006) Considerations for the design of intercepting drainage for collecting water from seep areas. J Irrig Drain Eng 132:597-599. https://doi.org/10.1061/ (ASCE)0733-9437(2006)132:6(597)

Chandio AS, Shui Lee T, Mirjat MS (2013) Simulation of horizontal and vertical drainage systems to combat waterlogging problems along the Rohri canal in Khairpur District, Pakistan. J Irrig Drain Eng 139(9):710-717. https://doi.org/10.1061/(ASCE) IR.1943-4774.0000590

Chau K (2006) A review on the integration of artificial intelligence into coastal modeling. J Environ Manag 80(1):47-57. https:// doi.org/10.1016/j.jenvman.2005.08.012

Fahmi A, Dabbagh Yarishah J, Hosseini Mansoub F (2015) Examining fundamental problems of APC canal concrete lining and strategies to solve them. Indian J Sci Technol 8(23):1-7. https ://doi.org/10.17485/ijst/2015/v8i23/74066

Gurovich L, Oyarce P (2015) Modeling agricultural drainage hydraulic nets. Irrig Drain Syst Eng 4:149-158. https://doi. org/10.4172/2168-9768.1000149

Jia Z, Luo W, Xie J, Pan Y, Chen Y (2011) Salinity dynamics of wetland ditches receiving drainage from irrigated agricultural land in arid and semi- arid regions. Agric Water Manag 100:9-17. https ://doi.org/10.1016/j.agwat.2011.08.026

Kroger R, Cooper CM, Moore M (2008) A preliminary study of an alternative controlled drainage strategy in surface drainage ditches: low-grade weir. Agric Water Manag 95:678-684. https ://doi.org/10.1016/j.agwat.2008.01.006

Naz B, Ale S, Bowling L (2009) Detecting subsurface drainage systems and estimating drain spacing in intensively managed agricultural landscapes. Agric Water Manag 96:627-637. https://doi. org/10.1016/j.agwat.2008.10.002

Nijland B, Croon F, Ritzema H (2005) Subsurface drainage practices guidelines for the implementation and operation. ILRI Publication, Wageningen

Nourani B, Salmasi F, Abbaspour A, Oghati Bakhshayesh B (2017) Numerical investigation of the optimum location for vertical drains in gravity dams. Geotech Geol Eng 35(2):799-808. https ://doi.org/10.1007/s10706-016-0144-1

Oyarce P, Gurovich L, Duarte V (2016) Experimental evaluation of agricultural drains. J Irrig Drain Eng 143(4):1-13. https://doi. org/10.1061/(ASCE)IR.1943-4774.0001134

Oyarce P, Gurovich L, Calderon I (2017) Simulating hydraulic behavior of an agricultural drain based on experimental data. J Irrig Drain Eng 1(1):1-8. https://doi.org/10.1061/(ASCE)IR.19434774.0001185

Palacios Velez OL, Cristobal Acevedo D, Nikolskii Gavrilov I, Landeros Sanchez C (2004) Application of two drain spacing formula for Mexico's humid tropical zone. J Irrig Drain Eng 130:70-77. https://doi.org/10.1061/(ASCE)0733-9437(2004)130:1(70)

Ritzema H, Nijland H, Croon A (2006) Subsurface drainage practices: from manual installation to large-scale implementation. Agric Water Manag 86:60-71. https://doi.org/10.1016/j.agwat .2006 .06 .026

Ritzema H, Satyanarayana T, Raman S, Boonstra J (2008) Subsurface drainage to combat waterlogging and salinity in irrigated lands in India: lessons learned in farmers' fields. Agric Water Manag 95(3):179-189. https://doi.org/10.1016/j.agwat.2007.09.012

Salmasi F, Khatibi R, Nourani B (2017) Investigating reduction of uplift forces by longitudinal drains with underlined canals. ISH J Hydraul Eng 1:1. https://doi.org/10.1080/09715010.2017.1350605

Samani N, Kompani Zare M, Seyyedian H (2006) Flow to horizontal drains in isotropic unconfined aquifers. J Hydrol 324:178-194. https://doi.org/10.1016/j/jhydrol.2005.10.003

Scholz M, Trepel M (2004) Hydraulic characteristics of groundwaterfed open ditches in a peatland. Ecol Eng 23:29-45. https://doi. org/10.1016/j.ecoleng.2004.06.011 
SEEP/W (2012) Seepage modeling with, an engineering methodology July 2012 edition, Geo-Slope International Ltd

Singh SK (2009) Generalized analytical solutions for groundwater head in a horizontal aquifer in the presence of subsurface drains. J Irrig Drain Eng 135(3):295-302. https://doi.org/10.1061/(ASCE) IR.1943-4774.0000150

Singh RM, Singh KK, Singh SR (2007) Water table fluctuation between drains in the presence of exponential recharge and depth-dependent evapotranspiration. J Irrig Drain Eng 133(2):183-187. https:// doi.org/10.1061/(ASCE)0733-9437(2007)133:2(183)

Stuyt L, Dierickx W, Beltran J (2005) Materials for subsurface land drainage systems. FAO, Rome
WinBo M, Arulrajah A, Horpibulsuk S, Chinkulkijniwat A, Leong M (2015) Laboratory measurements of factors affecting discharge capacity of prefabricated vertical drain materials. Soils Found 56(1):129-137. https://doi.org/10.1016/j.sandf.2016.01.010

Yamamoto Y, Hyodo M, Orense RP (2009) Liquefaction resistance of sandy soils under partially drained condition. J Geotech Geo Environ Eng 135(8):1032-1043. https://doi.org/10.1061/(ASCE) GT.1943-5606.0000051

Publisher's Note Springer Nature remains neutral with regard to jurisdictional claims in published maps and institutional affiliations. 